\title{
Spirituality in the Undergraduate Curricula of Nursing Schools in Portugal and São Paulo-Brazil
}

\author{
Sílvia Caldeira ${ }^{1, *}$, Amélia Simões Figueiredo ${ }^{1,+}{ }^{,}$, Ana Paula da Conceição ${ }^{2, \dagger}{ }^{+}$, Célia Ermel ${ }^{3,+}$, \\ João Mendes ${ }^{4,+}$, Erika Chaves ${ }^{5,+}{ }^{\text {, Emília Campos de Carvalho }}{ }^{6,+}$ and Margarida Vieira ${ }^{7,+}$ \\ 1 School of Nursing-Lisbon, Centre for Interdisciplinary Research in Health, \\ Universidade Católica Portuguesa-Instituto de Ciências da Sáude, Palma de Cima, Lisboa 1649-023, \\ Portugal; simoesfigueiredo@ics.lisboa.ucp.pt \\ 2 School of Health, Escola Superior de Saúde de Santa Maria, Porto 4049-024, Portugal; \\ ana.paula@santamariasaude.pt \\ 3 Faculty of Medicine and Nursing. Universidade de Marília, Av. Hygino Muzzy Filho, \\ 1001 Campus Universitário-Marília, São Paulo 03178-200, Brazil; reginaermel@unimar.br \\ 4 Nursing School of S. João de Deus, Universidade de Évora, Largo do Senhor da Pobreza, \\ Évora 7000-811, Portugal; jmendes@uevora.pt \\ 5 School of Nursing, Universidade Federal de Alfenas-UNIFAL-MG, Scholarship PET/MEC/SESU, \\ Alfenas-MG 37130-000, Brasil; echaves@unifal-mg.edu.br \\ 6 Ribeirão Preto College of Nursing-EERP-USP, University of São Paulo, São Paulo 03178-200, Brazil; \\ ecdcava@eerp.usp.br \\ 7 School of Nursing, Centre for Interdisciplinary Research in Health, \\ Universidade Católica Portuguesa-Instituto de Ciências da Sáude, Rua Diogo de Botelho, 1327, \\ Porto 4169-005, Portugal; mmvieira@porto.ucp.pt \\ * Correspondence: scaldeira@ics.lisboa.ucp.pt; Tel.: +351-217-214-147 \\ + The authors contributed equally to this work.
}

Academic Editor: John Swinton

Received: 15 September 2016; Accepted: 1 November 2016; Published: 8 November 2016

\begin{abstract}
Spirituality is considered a dimension of nursing care, which is often recognized as being neglected, mainly due to a lack of education. Several studies have addressed nursing students' perceptions and skills for providing spiritual care, but there is little evidence on how spirituality is addressed in undergraduate nursing curricula. This study comprised Portuguese and Brazilian nursing schools (from São Paulo) and describes how spirituality is addressed in undergraduate nursing curricula. It is descriptive and the survey research was performed in 2014-2015. The questionnaire was composed of closed and open-ended questions and was sent by e-mail. A total of 129 answers were obtained, mostly from Portugal. Results indicated that several curricular units include spirituality, although having different contents. The learning outcomes are consistent with improving nursing students' integral education, developing the clinical reasoning regarding spirituality, and improving the assessment of the patient across the life span. Nevertheless, it seems that spirituality is poorly addressed in clinical practice. Few nursing schools have courses or curricular units specifically dealing with spirituality, but they do provide some form of teaching on the subject. No standard curriculum exists, but teachers believe that it is a very important subject that should be included in the courses taught.
\end{abstract}

Keywords: spirituality; education; nursing; students; nursing; teaching; holistic nursing; cross-sectional studies 


\section{Introduction}

There is growing interest in spirituality and spiritual care in healthcare practice and in research [1-3]. Spirituality is a human dimension that is dynamic, integrative, multidimensional, and present in believers and non-believers [2-4]. Despite the discussion about the definition and the attributes of spirituality as a concept, the search for meaning in life is often pointed to as a core element [5,6], and is considered particularly important as a coping strategy at times of crisis and suffering [7]. For those who are religious, this is an important dimension of living their spirituality. Patients who are not religious also have spiritual experiences, considering that spirituality has a broader scope than religiosity and, as a human dimension, should be taken into serious consideration in healthcare [1,3]. The challenge is to bring the spiritual approach into nursing practice, which is often considered the "doing" and "being" component of nursing performance [8]. Recently, the concept of spiritual care was defined in seven attributes: a healing presence, therapeutic use of self, intuitive sense, exploration of the spiritual perspective, patient-centeredness, meaning-centred therapeutic intervention, and creation of a spiritually nurturing environment [9]. This definition emphasizes the importance of the nurse as a human being in the patient-nurse relationship, but also underlines the "therapeutic" intervention, which may comprise several nursing activities and other areas within the multidisciplinary healthcare team. Nurses usually describe their undergraduate training as poor or non-existent [10-16]. Other healthcare professionals also share this perception, such as occupational therapists [17], psychologists [18], and physicians or medical students [19-22]. A study of the teaching of spirituality in several Brazilian medical schools concluded that few schools have courses that specifically include spirituality, and less than half partially provide that content [20]. In the USA, only three medical schools in 1993 had included spirituality in their curricula, and this number has since increased by more than $80 \%$, as more than 100 medical schools now include spirituality in teaching and training [23].

Several experts underline the need to include spirituality in nursing teaching and clinical training [11-16], but the following barriers have also been identified: a reductionist approach to spirituality [10]; lack of time to provide spiritual care and to include spiritual assessment in clinical practice [6]; lack of knowledge about the concept of spirituality [14]; the absence of teaching programmes or guidelines [11-14]; lack of training of nursing teachers to support students in the assessment, diagnosis, planning, and definition of nursing outcomes related to spirituality [24,25].

Teachers are known as facilitators of the learning process, and this has also been deemed important before, also in the case of teaching spiritual care. The sense of absence regarding the teaching of spirituality might be transformed into an opportunity, by including spirituality in curricula and designing new programmes (contents and methods) to facilitate the learning process and the development of capabilities [26], and this should be included in all nursing curricula regardless of whether it is a Christian or state university [27].

Some syllabuses have been published in nursing literature, and common core concepts and themes are emphasized. However, there is no consensus regarding the best moment to introduce these contents, the most adequate methods, or even the teachers' capabilities for teaching these specific contents $[28,29]$. The teaching of spirituality seems to be a valuable strategy in the improvement of the quality of nursing care and an opportunity for spiritual development and to develop the skills relating to spiritual care. It is suggested that the inclusion of spirituality in nursing curricula may have a positive impact in three areas: personal impact (awareness of self, spirituality, and health); academic impact (improving the skills to provide spiritual care); and professional impact (better sensitivity to patients' spiritual needs and spiritual coping) [12].

The first publication about spirituality in nursing curricula dates from 1957, from the School of Nursing, University of Washington [11]. The interest in spirituality in nursing curriculum is not new. For example, a study in Canada was conducted in 2003 [30]. Research and scientific publications about spirituality have been progressively growing worldwide, and they have also taken big steps in Portugal [31] and in Brazil [32]. The research about spirituality in nursing in 
Portugal and Brazil usually includes educational aspects [28,33], ethical aspects regarding spiritual interventions [34,35], nursing diagnoses' validation [6-36], spiritual needs' assessment, and the validations of instruments $[37,38]$. Despite this evidence, little is known about the teaching of spirituality and spiritual care in undergraduate nursing schools in Portugal and Brazil. In fact, after conducting a literature review over 22 years, the authors underline that little work is done exploring nursing educators' perspectives and experiences about how to develop spiritual skills in their students [39].

The aim of this study was to study the current status of education in undergraduate nursing curricula concerning spirituality and spiritual care in Portugal and Brazil, including the analysis of the content of curricula, the objectives, the teaching methods, the learning results, the bibliography, the year/semester of teaching, and the nursing teachers' expertise.

\section{Methods}

Cross-sectional, descriptive, and survey research, using an electronic questionnaire, was performed from October 2014 to May 2015.

\subsection{Sample}

All Portuguese nursing schools and the nursing schools of the state of São Paulo in Brazil were screened for e-mail contacts. The information was found online on the schools' websites (in Brazil) and from the educational organizations (Portugal). A total of 40 nursing schools were identified in Portugal, and 89 in São Paulo, Brazil, and an e-mail was sent to the directors or coordinators providing information about the study background, aims, research team, and data collection instrument. They were asked to collaborate in sharing the instrument with all nursing teachers of the school, who were the participants in this study. The total number of teachers in the 129 schools has not been identified.

\subsection{Data Collection and Treatment}

An electronic questionnaire was created using Google Forms and was reviewed and tested by all the researchers, independently. An automatic sheet on Google was available and functional after the test, and all the data compiled. The questionnaire was composed of closed and open-ended questions regarding the characteristics of the nursing school (state, religious-concordata, private), and the number of students. The teaching of spirituality was addressed by the questions concerning when this area was taught (year, semester), in which curricular unit, the context, the objectives, the learning outcomes, the teaching methods and strategies, and the bibliography. Some questions regarding the respondent's opinion on the importance of spirituality in curricula were asked and whether spirituality was addressed in clinical practice. The questionnaire was available via an electronic link.

The information letter and the link to the questionnaire were sent to all contacts (e-mail addresses) of the nursing schools, and the collaboration of the directors requested. E-mails were sent on four occasions inviting participants to complete the questionnaire.

\subsection{Ethical Approval}

Participants were informed about the study and were free to accept whether or not to participate. The questionnaire was anonymous, and no question about the address or about the name of the nursing school was included, except the country (Portugal or Brazil). This study was registered and approved in "Plataforma Brasil" (number 35163514.7.0000.5496) and approved by the Ethics Committee of the Nursing School of Ribeirão Preto (number 946.309 10/02/2015). Two Portuguese and one Brazilian nursing school requested the full project to be analyzed by the institutional ethics committee, but no further answers were obtained. 


\section{Results}

A total of 129 answers to the questionnaire were obtained from working teachers, 80 (62.0\%) from Portugal and $49(38.0 \%)$ from Brazil. Most nursing schools are state-funded (55.8\%), while the rest are private $(33.3 \%)$ and Concordata $(10.9 \%)$. More than half are integrated in universities $(51.9 \%), 29.5 \%$ are not integrated, and less are in polytechnic institutes (18.6\%). When asked if spirituality was included in the curriculum, $38.8 \%$ said it was, but almost the same number said no $(34.9 \%)$, and $26.4 \%$ chose to answer, "I am not sure." Among the 119 participants who answered the question about whether they usually include spirituality in their own curricular units or courses, 11 said they did, 43 said they didn't, and the majority $(n=65)$ chose to answer "sometimes." When asking to justify why they did not include spirituality in the discipline, no answer was obtained. Most of the curricular units including the approach to spirituality are obligatory and few are optional. The questions about the year and semester were rarely answered. Several curricular units, contents, methods, learning outcomes, and bibliography including spirituality were described (Table 1).

Table 1. Curricular units, contents, methods, and learning outcomes regarding the inclusion of spirituality in the curriculum.

\begin{tabular}{ll}
\hline \multicolumn{1}{c}{ Inclusion of Spirituality in the Curriculum } \\
\hline & $\begin{array}{l}\text { fundamentals of nursing; nursing theories; epistemology; adult and elderly nursing; } \\
\text { communication; nurse-patient helping relationship; clinical practice; complementary } \\
\text { therapies; professional ethics; nursing in continuity care; palliative care nursing and } \\
\text { continuous care; family and society; nursing history; mental health; death and dying; } \\
\text { human development; theology and culture; nursing in critical care. }\end{array}$ \\
\hline & $\begin{array}{l}\text { meaning of life and illness; spirituality and spiritual care; nursing diagnoses and } \\
\text { interventions related to spirituality; analysis of research; assessment of spiritual needs; } \\
\text { resilience; respect for religious beliefs; freedom; death and the dying process; spirituality } \\
\text { and religiosity; including spiritual care in clinical practice; managing chronic illness in } \\
\text { adult and children; culture and beliefs; communication and bad news; post mortem care; } \\
\text { holistic assistance; therapeutic communication; compassion in healthcare. }\end{array}$ \\
\hline \multirow{2}{*}{ Methods } & $\begin{array}{l}\text { drama; role playing; case study and discussion; search in databases and research analysis; } \\
\text { journaling; tutorial supervision; oral presentation of contents; group dynamics; } \\
\text { film analysis; text analysis. }\end{array}$ \\
\hline \multirow{2}{*}{ Learning Outcomes } & $\begin{array}{l}\text { improve integral education; integrate the clinical reasoning regarding spirituality; } \\
\text { improve the assessment of the patient across the life span. }\end{array}$ \\
\hline
\end{tabular}

Among the 67 answers about the approach to spirituality in clinical practice, the majority ( $\mathrm{n}=24)$ chose the option "poorly addressed," 20 chose "always," and 19 "sometimes." Nevertheless, all 129 participants answered the question about the importance of including spirituality in nursing curricula, and $62.0 \%$ considered it to be very important, $31.8 \%$ important, and $8.0 \%$ of little importance.

Three participants from Brazil completed the open-ended question at the end of the questionnaire asking for additional comments on the questionnaire. These participants congratulated the team on the research subject and highlighted the importance of exploring spirituality. That they underlined it is often absent from curricula design and nursing students' education.

\section{Discussion}

This is a novel study on the inclusion of spirituality; to our knowledge, no other study has been conducted on this topic in Brazil or Portugal. Twenty years ago, there was a dearth of research exploring the experiences and concerns of nursing educators in relation to spiritual care concepts in nursing education $[10,11]$, which still seems to be the case [39]. This study provides a description of several elements related to curricula, and the results have provided valuable information that could be helpful for planning nursing curricula, teaching and further research. It can also be useful from 
the nursing educators' perspective, as most of the research has been conducted with undergraduate students and nurses.

The importance of addressing spirituality in worldwide healthcare curricula has become paramount in several disciplines, but no specific or structured guidance has been provided. Most studies have been focused on asking students about their preparedness to provide spiritual care, but with no overall focus. In a study conducted in Northern Ireland, more than $90 \%$ of medical students indicated that they had not received any formal training in providing spiritual care to patients [21]. The same is concluded by a qualitative study in Iran about the inclusion of spirituality in medical education [40]. Researchers from Australia conducted a systematic literature review to identify studies exploring the physician's perspective on the discussion of religion, spirituality at medical appointments, or both, and they concluded that these topics are infrequently discussed, but the frequency increases in cases of terminal illness. Additionally, many physicians prefer to make chaplain referrals for discussing religion or spirituality with patients [22]. Insufficient time and training were the most frequently reported barriers in this review, leading the authors to conclude that more training is needed [22]. A similar situation can be found in nursing education. In a recent literature review specifically addressing nursing education, the authors state that acknowledging spirituality opens up a new horizon of nursing education skills, and more knowledge is needed regarding nursing teachers' competencies and their preparedness for this [39]. Spirituality can be associated with the word "neglect" when discussing the nursing education provided over the last 20 years $[11,16]$. Moreover, conceptual confusion still seems to exist, and spirituality is rarely defined or clearly included in the objectives [30].

In this study, most respondents said they were not sure or confirmed that spirituality was not included in the curriculum. Interestingly, the majority of those who responded said that they usually include spirituality in their curricular units. The number of participants was lower than expected, and this may be due to several reasons. We emphasize that those who are connected to this subject or those who have a particular interest in the educational aspects of nursing probably felt more enthusiastic about filling in the questionnaire. Nevertheless, the workload for nursing teachers to revise existing curriculum has been considered a barrier to education in this area $[10,41]$. Regardless of the expertise and competencies of nursing teachers in specific areas, it seems there is a need to discuss nursing curricula in their global dimension and to clearly define when, how, and by whom spirituality is to be addressed. The respondents of this study rarely answered the question regarding the semester or year when spirituality was addressed. However, they stated several curricular units and contents in which they believe spirituality is addressed. The units range from the fundamentals (fundamentals of nursing; nursing theories; epistemology; professional ethics; nursing history; communication; nurse-patient helping relationship) to specific clinical contexts (clinical practice; adult and elderly nursing; nursing in continuity care; palliative care nursing and continuous care; nursing in critical care; mental health) and cross-cutting curricular units and knowledge (complementary therapies; family and society; death and dying; human development; theology and culture; human development). Regardless of the curricular units in which respondents believe spirituality is addressed, the study of nursing textbooks in the USA and Ireland concluded that the content regarding spirituality was poor [42,43]. The integration of social and humanities disciplines such as philosophy, phenomenology, anthropology, and art could be one way of developing these skills in students $[39,44]$. Most respondents agreed that spirituality should be addressed in the undergraduate curriculum, but the number of curricular units and contents may give rise to difficulties defining what spirituality is and what topics it should comprise. Nevertheless, some syllabuses that have previously been published share common contents. These include generic topics such as the definitions and attributes of health; the definitions of spirituality in a multidisciplinary context and its heritage in healthcare; the definition of spiritual care and ethical aspects in providing spiritual care; the influence and the impact of spirituality on patient health; the importance of spirituality in health and illness transitions; the specificity of religious aspects and the customs of the major world faiths; 
instruments for assessing spirituality; healthcare resources in providing spiritual care; self-awareness and own spirituality $[21,28,29]$.

In regard to the teaching methods, the respondents described innovative and dynamic examples. In some way, all methods evoke discussion and reflection (case study and discussion; oral presentation of contents; film analysis; text analysis; journaling), empathy and skills training (drama; role playing; groups dynamics), and the scientific component of the study of spirituality (search in databases and research analysis; tutorial supervision). Other studies on medical students concluded that theoretical concepts would be adequate in the initial years of the undergraduate course, backed by talks delivered by patients and clinicians sharing personal experiences of their own spirituality [21]. There is little consensus as to whether training should be compulsory or optional, but the same authors suggest that it should be mandatory for medical students in the final years of training to spend a day shadowing a chaplain on a hospital ward [21]. Self-awareness and own spirituality is mandatory for the provision of spiritual care and being able to integrate spirituality into clinical practice $[4,14]$. Journaling, reflection, and tutorial supervision are important for helping students to obtain in-depth knowledge and awareness of their own spirituality and identity. For medical students, small group teaching sessions and reflective portfolios were considered the most appropriate assessment tool [21]. The same has been reported in nursing education [28,29]. Additionally, in a well-founded theory to investigate how nursing educators prepare students to assess and address spirituality, role-modeling and mentoring were also emphasized [45]. Other particular strategies in the teaching of spirituality have been reported, such as caring for patients in different clinical placements, i.e., while on a religious pilgrimage [46]. The support and teaching of spirituality, as a subjective and abstract concept, should start from the first year. Some authors define the nursing course as a spiritual journey and state that nursing educators should have embarked on that journey, exploring our inner essence, self-awareness, and revealing the essential spiritual principles that underpin teaching practices [47]. Once educated via a self-study program, nurses and nursing students revealed changes in their attitude towards spiritual care, but nursing students were more willing to communicate with patients in spiritual distress than nurses [48]. Nursing students expect teachers to help them develop the skills to provide spiritual care $[49,50]$, and no doubts should remain whether spirituality should be taught $[12,48]$. Indeed, a significant difference in the knowledge and attitudes toward spirituality of nursing students was reported as a result of the integration of spirituality into the undergraduate nursing curriculum [51].

The number of participants was not as high as expected, considering the number of nursing schools identified in advance. However, caution is needed when analyzing the number of schools, as some Brazilian schools, particularly private schools, have different units in different places in the state of São Paulo sharing the same curriculum. This was not possible to assess because the questionnaire only established the country. The total number of nursing teachers in all schools was unknown, so caution is needed when reading the descriptive results. Qualitative research based on interviewing nurse educators from each country would provide further valuable information to improve the curricula and teaching strategies adapted to the local and cultural context. Moreover, further research with nursing students regarding their skills for providing specific spiritual care could be helpful in curricula design for the student-centred approach.

\section{Conclusions}

Nurses are professionally and ethically responsible for providing spiritual care within the healthcare team, so adequate education and preparation are required during undergraduate learning. The spiritual needs of patients are widely known and nursing students should be prepared to assess and adequately intervene. It is time to start transferring research evidence to practice in nursing education and to effectively include spirituality and spiritual care skills in undergraduate nursing syllabuses. Nursing undergraduate curricula should include specific theoretical and clinical-based spiritual care contents, timings, and strategies. 
Acknowledgments: The authors are grateful to those who provided assistance checking the e-mails of the institutions in both countries, to those who participated in this study, and particularly to the School of Health-Escola Superior de Saúde de Santa Maria, Porto for supporting this publication.

Author Contributions: Sílvia Caldeira, Amélia Simões Figueiredo, Ana Paula da Conceição, Regina Célia Ermel, João Mendes, Érika Chaves, Emília Campos de Carvalho, and Margarida Vieira conceived, designed, and performed the study; Sílvia Caldeira and Amélia Simões Figueiredo analyzed the data; Sílvia Caldeira, Amélia Simões Figueiredo, Ana Paula da Conceição, Célia Ermel, João Mendes, Érika Chaves, Emília Campos De Carvalho, and Margarida Vieira wrote the paper.

Conflicts of Interest: The authors declare no conflict of interest.

\section{References}

1. Suzette Brémault-Phillips, Joanne Olson, Pamela Brett-MacLean, Doreen Oneschuk, Shane Sinclair, Ralph Magnus, Jeanne Wei, Marjan Abbasi, Jasneet Parmar, and Christina M. Puchalski. “Integrating Spirituality as a Key Component of Patient Care." Religions 6 (2015): 476-98. [CrossRef]

2. Sílvia Caldeira, Emília Campos de Cravalho, and Margarida Vieira. "Spiritual Distress-Proposing a New Definition and Defining Characteristics." International Journal of Nursing Knowledge 24 (2013): 77-84. [CrossRef] [PubMed]

3. Harold Koenig. Spirituality and Health Research: Methods, Measurement, Statistics, E Resources. Philadelphia: Templeton Foundation Press, 2011.

4. Wilfred McSherry. "The principal components model: A model for advancing spirituality and spiritual care within nursing and health care practice." Journal of Clinical Nursing 15 (2006): 905-17. [PubMed]

5. Elizabeth Weathers, Geraldine McCarthy, and Alice Coffey. "Concept analysis of spirituality: An evolutionary approach." Nursing Forum 51 (2016): 79-96. [CrossRef] [PubMed]

6. Sílvia Caldeira, Fiona Timmins, Emília Campos de Carvalho, and Margarida Vieira. "Clinical validation of the nursing diagnosis spiritual distress in cancer patients undergoing chemotherapy." International Journal of Nursing Knowledge, 2016. [CrossRef] [PubMed]

7. Donia Baldacchino, and Peter Draper. "Spiritual coping strategies: A review of the nursing research literature." Journal of Advanced Nursing 34 (2001): 833-41. [CrossRef] [PubMed]

8. Sílvia Caldeira, and Fiona Timmins. "Editorial: Time as presence and opportunity: The key to spiritual care in contemporary nursing practice." Journal of Clinical Practice 24 (2015): 2355-56. [CrossRef] [PubMed]

9. Monir Ramezani, Fazlollah Ahmadi, Eesa Mohammadi, and Anoshirvan Kazemnejad. "Spiritual care in nursing: A concept analysis." International Nursing Review 61 (2014): 211-19. [CrossRef] [PubMed]

10. Wilfred McSherry, and Peter Draper. "The spiritual dimension: Why the absence within nursing curricula?" Nurse Education Today 17 (1997): 413-17. [CrossRef]

11. Linda Ross. "Teaching spiritual care to nurses." Nurse Education Today 16 (1996): 38-43. [CrossRef]

12. Donia Baldacchino. "Teaching on the spiritual dimension in care: The perceived impact on undergraduate nursing students." Nurse Education Today 28 (2008): 501-12. [CrossRef] [PubMed]

13. Donia Baldacchino. "Teaching on the spiritual dimension in care to undergraduate nursing students: The content and teaching methods." Nurse Education Today 28 (2008): 550-62. [CrossRef] [PubMed]

14. René van Leeuwen, Lucas J. Tiesinga, Berrie Middel, Doeke Post, and Henk Jochemsen. “The effectiveness of an education programme for nursing students on developing competence in the provision of spiritual care." Journal of Clinical Nursing 17 (2008): 2768-81. [CrossRef] [PubMed]

15. Cynthia I. Shores. "Spiritual perspectives of nursing students." Nurse Education Perspective 31 (2010): 8-12.

16. Linda Ross, Rene van Leeuwen, Donia Baldacchino, Tove Giske, Wilfred McSherry, Aru Narayanasamy, Carmel Downes, Paul Jarvis, and Annemiek Schep-Akkerman. "A student nurses perceptions of spirituality and competence in delivering spiritual care: A European pilot study." Nurse Education Today 34 (2014): 697-702. [CrossRef] [PubMed]

17. Thuli Godfrey Mthembu, Nicolette Roman, and Lisa Wegner. "A cross-sectional descriptive study of occupational therapy students' perceptions and attitudes towards spirituality and spiritual care in occupational therapy education." Journal of Religion and Health 55 (2016): 1529-45. [CrossRef] [PubMed]

18. Cassandra Vieten, Ron Pilato, Shelley Scammell, and Ingrid Ammondson. "Spiritual and religious competencies for psychologist." Psychology of Religion and Spirituality 5 (2013): 129-44. [CrossRef] 
19. Harold Koenig, Alizabeth Hooten, and Erin Lindsay-Calkins. "Spirituality in medical school curricule: Findings from a national survey." International Journal of Psychiatry in Medicine 40 (2010): 391-98. [CrossRef] [PubMed]

20. Giancarlo Lucchetti, Alessandra Lucchetti, Daniele Espinha, Leandro Oliveira, José Leite, and Harold Koenig. "Spirituality and health in the curricula of medical schools in Brazil." BMC Medical Education 12 (2012): 78. [CrossRef] [PubMed]

21. Mark Harbinson, and David Bell. "How should teaching on whole person medicine, including spiritual issues, be delivered in the undergraduate medical curriculum in the United Kingdom?" BMC Medical Education 15 (2015): 96. [CrossRef] [PubMed]

22. Megan Best, Phyllis Butow, and Ian Olver. "Doctors discussing religion and spirituality: A systematic literature review." Palliative Medicine 30 (2016): 327-37. [CrossRef] [PubMed]

23. Mark Cobb, Christina Puchalsky, and Bruce Rumbold. Oxford Textbook of Spirituality and Health. New York: oxford University Press, 2012.

24. Corinne Lemmer. "Teaching the spiritual dimension of nursing care: A survey of U.S. baccalaureate nursing programs." Journal of Nursing Education 41 (2002): 482-90. [PubMed]

25. Meredith Wallace, Suzanne Campbell, Sheila C. Grossman, Joyce M. Shea, Jean W. Lange, and Theresa T. Quell. "Integrating spirituality into undergraduate nursing curricula." International Journal of Nursing Education Scholarship 5 (2008): 1-13. [CrossRef] [PubMed]

26. Ana Maria Catanzaro, and Kathleen McMullen. "Increasing nursing students' spiritual sensitivity." Nurse Educator 26 (2001): 221-26. [CrossRef] [PubMed]

27. Jennifer Gray, Linda Garner, Diane Snow, and Kathy Wright. "Spiritual perspective and needs: A comparative study of nursing faculty in a Christian university and a state university." Christian Higher Education 3 (2004): 61-77. [CrossRef]

28. Sílvia Caldeira. "A espiritualidade no curriculo de enfermagem." Nursing Portuguesa Jul/Ag (2012): 18-21.

29. Tove Giske. "How undergraduate nursing students learn to care for patients spiritually in clinical studies-A review of literature." Journal of Nursing Management 20 (2012): 1049-57. [CrossRef] [PubMed]

30. Joanne Olson, Pauline Paul, Lillian Douglas, Margaret Clark, Jane Simington, and Nancy Goddard. "Addressing the spiritual dimension in Canadian undergraduate nursing education." Canadian Journal of Nursing Research 35 (2003): 94-107. [PubMed]

31. Sílvia Caldeira, Zita Castelo Branco, and Margarida Vieira. "Spirituality in nursing care: A review of scientific publication in Portugal." Referência 5 (2011): 145-52. [CrossRef]

32. Rodolfo Damiano, Lucas Costa, Marcos Viana, Alexandre Moreira-Almeida, Alessandra Lucchetti, and Giancarlo Lucchetti. "Brazilian scientific articles on 'spirituality, religion and health'." Archives of Clinical Psychiatry 43 (2016): 11-16.

33. Paphael Pedrão, and Ruth Beresin. “O enfermeiro frente à questão da espiritualdiade.” Einstein 8 (2010): 86-91. [CrossRef] [PubMed]

34. Sílvia Caldeira. "Spiritual care: Prayer as a nursing intervention." Cuid'Arte Enfermagem 3 (2009): 157-64.

35. Caroline Guilherme, Gabriela Roberta Ribeiro, Ślvia Caldeira, Cristina Mara Zamarioli, Ana Railka de Souza Oliveira-Kumakura, Ana Maria Almeida, and Emilia Campos de Carvalho. "Effect of the 'Spiritual Support' Intervention on Spirituality and the Clinical Parameters of Women Who Have Undergone Mastectomy: A Pilot Study." Religions 7 (2016): 26. [CrossRef]

36. Erika Chaves, Emília Campos de Carvalho, Fabio Terra, and Luis de Sousa. “Clinical validation of impaired spirituality in patients with chronic renal disease." Revista Latino Americana de Enfermagem 18 (2010): 309-16. [CrossRef]

37. Erika Chaves, Emilia Campos de Carvalho, Rosana Dantas, Fábio Terra, Denis Nogueira, and Luiz de Souza. "Validation of Pinto and Pais-Ribeiro's spirituality scale in patients with chronic renal insufficiency in hemodialysis." Revista de Enfermagem UFPE on Line 4 (2010): 715-21. [CrossRef]

38. Cândida Pinto, and José Luís Pais-Ribeiro. "Construção de uma escala de avaliação da espiritualidade em contextos de saúde." Arquivos de Medicina 21 (2007): 47-53.

39. Gulnar Ali, John Wattis, and Michael Snowden. "'Why are spiritual aspects of care so hard to address in nursing education?' A literature review (1993-2015)." International Journal of Multidisciplinary Comparative Studies 2 (2015): 7-31. 
40. Nadereh Memaryan, Maryam Rassouli, Seyedeh Nahardani, and Parisa Amiri. "Integration of spirituality in medical education in Iran: A qualitative exploration of requirements." Evidence-Based Complementary and Alternative Medicine, 2015. Available online: https://www.hindawi.com/journals/ecam/2015/793085/abs/ (accessed on 2 September 2016).

41. Lesline P. Lewinson, Wilfred McSherry, and Peter Kevern. "Spirituality in pre-registration nurse education and practice: A review of the literature." Nurse Education Today 35 (2015): 806-14. [CrossRef] [PubMed]

42. Fiona Timmins, Marianne Murphy, Freda Neill, Cecily Begley, and Greg Sheaf. "An exploration of the extent of inclusion of spirituality and spiritual care concepts in core nursing textbooks." Nurse Education Today 35 (2015): 277-82. [CrossRef] [PubMed]

43. Melanie McEwen. "Analysis of spirituality content in nursing textbooks." Journal of Nursing Education 43 (2004): 20-30. [PubMed]

44. Patricia Benner, Molly Sutphen, Victoria Leonard, Lisa Day, and Lee Shulman. Educating Nurses: A Call for Radical Transformation. San Francisco: Wiley, 2010.

45. Pamela Cone, and Tove Giske. "Teaching spiritual care-A grounded theory study among undergraduate nursing educators." Journal of Clinical Nursing 22 (2013): 1951-60. [CrossRef] [PubMed]

46. Donia Baldacchino. "Caring in Lourdes: An innovation in students' clinical placement." British Journal of Nursing 19 (2010): 358-66. [CrossRef] [PubMed]

47. Michelle Spadoni, and Patricia Sevean. "Relational Inquiry-Attending to the spirit of nursing students." Religions 7 (2016): 34. [CrossRef]

48. Elizabeth Taylor, Iris mamier, Khaled Bahjri, Triin Anton, and Floyd Petersen. "Efficacy of a self-study programme to teach spiritual care." Journal of Clinical Nursing 18 (2008): 1131-40. [CrossRef] [PubMed]

49. Annette Becker. "Ethical considerations of teaching spirituality in the academy." Nursing Ethics 16 (2009): 697-706. [CrossRef] [PubMed]

50. Asli Kalkim, Tulay Midilli, and Ebru Baysal. "An investigation of the perceptions and practices of nursing students regarding spirituality and spiritual care." Religions 7 (2016): 101. [CrossRef]

51. Meryem Yilmaz, and Hesna Gurler. "The efficacy of integrating spirituality into undergraduate nursing curricula." Nursing Ethics 21 (2014): 929-45. [CrossRef] [PubMed]

(C) 2016 by the authors; licensee MDPI, Basel, Switzerland. This article is an open access article distributed under the terms and conditions of the Creative Commons Attribution (CC-BY) license (http://creativecommons.org/licenses/by/4.0/). 